\title{
Prickly food: snakes preying upon porcupines
}

\author{
Marcelo Ribeiro Duarte \\ Laboratório de Herpetologia, Instituto Butantan, Av. Vital Brazil, 1500, 05503-900, São Paulo, SP, Brazil. \\ E-mail: mrduarte@butantan.gov.br.
}

Keywords: Serpentes, porcupines as prey, hazardous preys, injuries on snakes, feeding behavior.

Large snakes, like Python molurus, $P$. sebae and $P$. reticulatus, are able to prey on horned mammals with potential to cause serious injuries when swallowed. Those preys include small to medium-sized bovids such as Kobus kob (Hay and Martin 1966), Aepyceros melampus (Gasc 1994), Axis porcinus, Gazella thomsoni, Muntiacus muntjac (Greene 1997), and antelopes (Spawls and Branch 1995). Porcupines are other type of potentially harmful prey due to their pointed quills, which may cause serious injuries when swallowed by snakes. Domestic and wild animals may be fatally injured or become unable to feed due to quill punctures after an encounter with a porcupine (Nowak 1991).

This paper deals with porcupines as snake prey and is based both on published and original data. Original data was obtained upon snake specimens arrival at the Laboratório de Herpetologia, Instituto Butantan, São Paulo, southeastern Brazil, by sporadic suppliers, as well as on specimens collected during fieldwork. Because quills are keratinous and sharp, they remain undigested and are easily detectable in

Received 15 September2003.

Accepted 10 N ovember2003.

Distributed 19 December 2003. the gut (sometimes they pierce the snake's body). Additional evidence of porcupine-eating snakes (e.g., quills in feces) comes from occasional observations of captive snakes.

Predation on porcupines has been recorded for species in Boidae, Pythonidae, Colubridae, Elapidae, and Viperidae. Data presented herein include preying attempts and actual predation, as well as potential defensive strikes on porcupines (Table 1).

Boidae and Viperidae were the two families with most records for this encounter type, and Boa constrictor was the species most frequently recorded (Table 1). In one instance, the porcupine quills pierced the stomach and body walls of the Boa constrictor amarali (Cherubini et al. 2003). Snakes recorded meeting porcupines are diurnal, crepuscular/nocturnal, or both, but only in Spilotes pullatus mexicanus (Köhler and Seipp 1999) the time of behavioral context was recorded.

Snake species in the Boidae, Pythonidae, Colubridae, Viperidae, and Elapidae occasionally meet and even prey on porcupines in Africa, America, and Asia. Boids and viperids are the two families with most records for these encounters. Although a defensive strike should be considered in two cases (Bothrops jararaca and Crotalus durissus, Figure 1), attempts or 
Table 1 - Summary of snake encounters with porcupines under several circumstances. A, adult snake; TL, total length.

\begin{tabular}{|c|c|c|c|c|c|}
\hline SNAKE SPECIES & $\begin{array}{l}\text { TOTAL LENGTH } \\
(\mathrm{mm})\end{array}$ & $\begin{array}{c}\text { PREY } \\
\text { SPECIES }\end{array}$ & $\begin{array}{l}\text { INJ URIES ON } \\
\text { SNAKES }\end{array}$ & CIRCUMSTANCES & REFERENCES \\
\hline Boa constrictor amarali (A) & ca. 1200 & Coendou sp. & No injuries detected & $\begin{array}{l}\text { Hair and quills } \\
\text { defecated }\end{array}$ & This paper \\
\hline Boa constrictor amarali (A) & ca. $1600^{*}$ & "Porcupine" & $\begin{array}{l}\text { Quills in stomach } \\
\text { and body cavity }\end{array}$ & $\begin{array}{l}\text { Death due to quill } \\
\text { injuries }\end{array}$ & $\begin{array}{l}\text { Cherubini et al. } \\
2003 / \text { *pers. com }\end{array}$ \\
\hline Boa constrictor imperator (A) & ca. 1800 & C. rothschildi & $\begin{array}{l}\text { Quills piercing oral } \\
\text { cavity }\end{array}$ & $\begin{array}{l}\text { Hair, claws and } \\
\text { quills defecated }\end{array}$ & Tschambers 1949 \\
\hline Corallus hortulanus (?) & $?$ & Coendou sp. & $\begin{array}{l}\text { Quills piercing the } \\
\text { body }\end{array}$ & Dying on the ground & Argôlo 1992 \\
\hline Python reticulatus (A) & $?$ & $\begin{array}{c}\text { Hystrix } \\
\text { brachyura }\end{array}$ & $?$ & Stomach content* & $\begin{array}{c}\text { Shine et al. 1998/ } \\
\text { *pers. com. }\end{array}$ \\
\hline Spilotes pullatus (A) & 2175 & $\begin{array}{l}\text { Sphiggurus } \\
\text { mexicanus }\end{array}$ & $\begin{array}{l}\text { Quills piercing oral } \\
\text { cavity, tail, body. }\end{array}$ & $\begin{array}{l}\text { Trying to swallow } \\
\text { prey }(11: 00 \mathrm{~h})\end{array}$ & $\begin{array}{c}\text { Köhler and Seipp } \\
1999\end{array}$ \\
\hline Ophiophagus hannah (?) & $?$ & Hystrix indica & $?$ & $?$ & Krishna 2002 \\
\hline Bitis gabonica $(\mathrm{A})$ & $?$ & $\begin{array}{l}\text { Atherurus } \\
\text { africanus }\end{array}$ & $?$ & $?$ & Greene 1997 \\
\hline Bothrops jararaca (A) & ca. 900 & Coendou sp. & $\begin{array}{l}\text { Quills piercing oral } \\
\text { cavity }\end{array}$ & $\begin{array}{l}\text { Predatory or } \\
\text { defensive strike }\end{array}$ & This paper \\
\hline Crotalus durissus (A) & ca. 800 & Coendou sp. & $\begin{array}{l}\text { Quills piercing oral } \\
\text { cavity }\end{array}$ & $\begin{array}{l}\text { Predatory or } \\
\text { defensive strike }\end{array}$ & This paper \\
\hline
\end{tabular}

successful predation on porcupines is recorded for one African viperid (Bitis gabonica). However, it should be noted that this latter viper is much more robust and has a much more wide gap than the two neotropical species.

There is no apparent relation between porcupines' activity period or preferred habitat (Nowak 1991) and the encounters with, or predation by the snakes. Avoidance of specific prey types is common among predators and drives the evolution of mimicry systems and aposematic signals in the prey (Brodie III and Brodie Jr. 1999). Even if the presence of spines and other mechanical defenses may serve as a warning display to visual predators (Endler
1986), this may not work for some snakes, which are mostly thermal or chemosensory guided predators (Ford and Burghardt 1993). The consequences for a snake swallowing a prey armed with quills may be hazardous or even mortal. However, chemical, visual, and tactile stimuli apparently do not preclude predation on porcupines by Boa constrictor (Tschambers 1949, Cherubini et al. 2003, this paper), Python reticulatus (Shine et al. 1998) and Spilotes pullatus mexicanus (Köhler and Seipp 1999). Notwithstanding the snakes' sensorial tactics and some degree of diet versatility (Greene 1997), I suggest that porcupines are not rejected by these predators as a potentially hazardous 

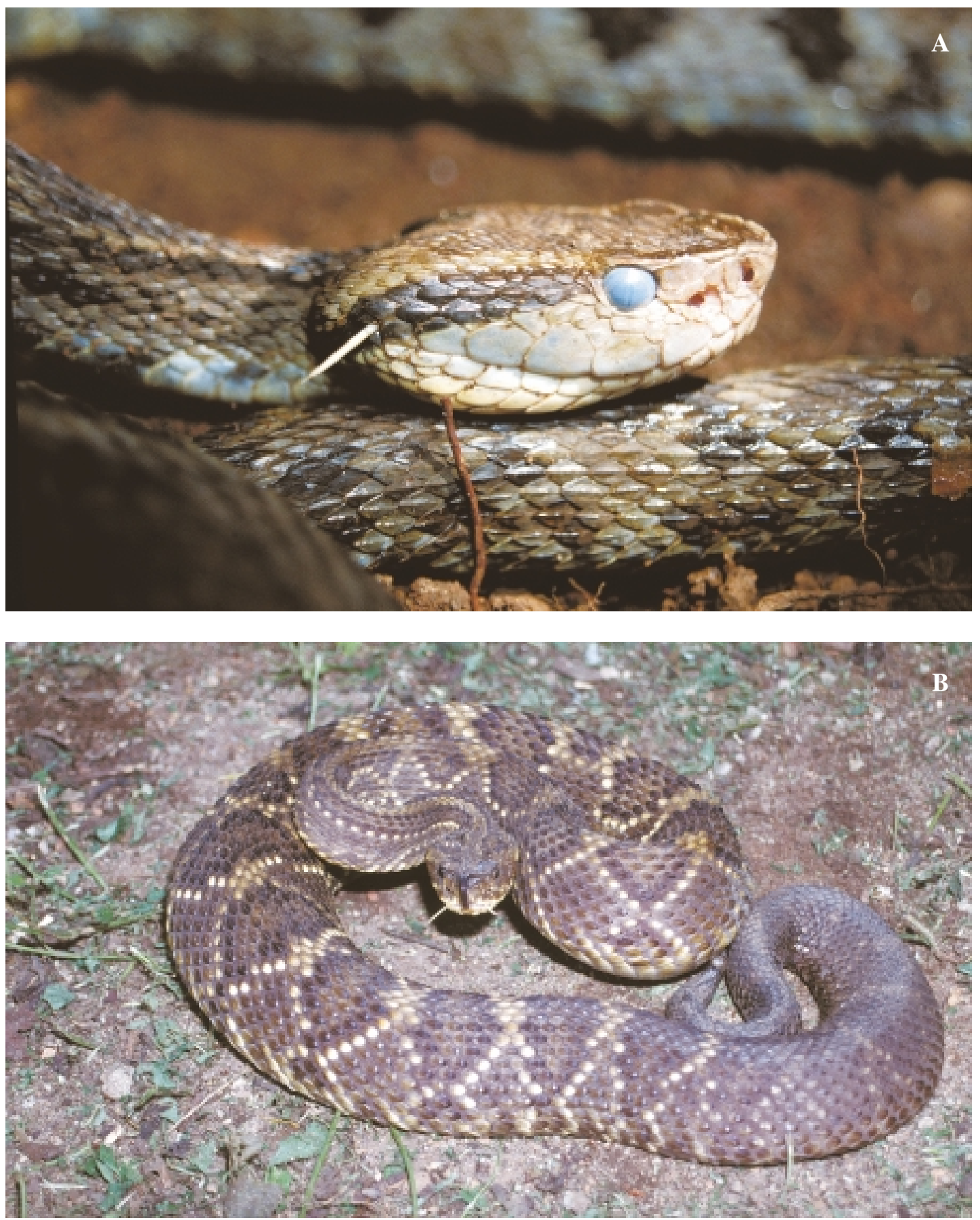

Figure 1 - Quills of the porcupine Coendou sp. piercing mouth of the viperid snakes Bothrops jararaca (A) and Crotalus durissus (B).

Phyllomedusa - 2(2), December 2003 
prey, and may even be recognized as an "ordinary", large rodent. Porcupines are possibly ambushed by the snakes and thus are unable to display or enhance their warning signals to avoid predation.

\section{Acknowledgements}

The author thanks Richard Shine for additional information on $P$. reticulatus predation and comments on the manuscript, T. H. Barrella for additional information on Boa constrictor amarali size, and an unknown referee for suggestions and improving the text.

\section{References}

Argôlo, A. J. S. 1992. Considerações sobre a ofiofauna dos cacauais do sudeste da Bahia, Brasil. Unpublished Report, Universidade Estadual Santa Cruz, Ilhéus, BA, Brazil. 64 pp.

Brodie III, E. D. and E. D. Brodie Jr. 1999. Predator-prey arms races: asymmetrical selection on predators and prey may be reduced when prey are dangerous. BioScience 49: 557-568.

Cherubini, A. L., T. H. Barrella and R. J. Silva. 2003. Death of Boa constrictor amarali (Serpentes, Boidae) after ingestion of a tree porcupine (Rodentia). Journal of Venom Animals and Toxins 9: 117-124.
Endler, J. A. 1986. Defense against predators. Pp. 109-134 in M. E. Feder and G. V. Lauder (eds.), Predator-Prey Relationships - perspectives and approaches from the study of lower vertebrates. Chicago. The University of Chicago Press.

Ford, N. B. and G. M. Burghardt. 1993. Perceptual mechanisms and the behavioral ecology of snakes. Pp. 117-164 in R. A. Seigel and J. T. Collins (eds.), Snakes - ecology and behavior. New York. McGraw-Hill.

Gasc, J-P. 1994. Predation and nutrition. Pp. 108-121 in R. Bauchot (ed.), Snakes - a natural history. New York. Sterling Publishing.

Greene, H. 1997. Snakes - the evolution of mistery in nature. Berkeley. University of California Press. 351 pp.

Hay, P. W. and P. W. Martin. 1966. Python predation on Uganda kob. East African Wildlife Journal 4: 151-52.

Köhler, G. and R. Seipp. 1999. Spilotes pullatus (Tiger Ratsnake). Prey. Herpetological Review 30: 104.

Krishna, S. B. 2002. Ophiophagus hannah (King Cobra). Diet. Herpetological Review 33: 141.

Nowak, R. M. 1991. Walker's Mammals of the World. 5th ed. Baltimore. The Johns Hopkins University Press. 1629 pp.

Shine, R., P. S. Harlow, J. S. Keogh, and Boeadi. 1998. The influence of sex and body size on food habits of a giant tropical snake, Python reticulatus. Functional Ecology 12: 248-258.

Spawls, S. and B. Branch. 1995. The Dangerous Snakes of Africa. Sanibel Island, Fl. Ralph Curtis Books. 192 pp.

Tschambers, B. 1949. Boa constrictor eats porcupine. Herpetologica 5: 141. 